\title{
Vestígios Étnicos na Península de São José do Norte RS: Memória, Cultura e Identidade Luso-Brasileira
}

\author{
Rastros étnicos en la Península de San José do Norte RS: Memoria, \\ Identidad y Cultura luso-brasileña
}

\author{
Ethnic traces in the Peninsula of São José do Norte RS: Memory, Culture \\ and Luso-Brazilian Identity
}

\begin{abstract}
Ma. Alessandra Buriol Farinha ${ }^{1}$
Resumo

O trabalho objetiva refletir sobre alguns aspectos da memória social e identidade cultural na península de São José do Norte, RS, especificamente traços da etnia açoriana. Os açorianos ocuparam a região em meados do século XVIII, trazendo para terras rio-grandenses modos de vida, tradições e culturas que, incorporadas aos hábitos locais existentes, formaram uma identidade luso-brasileira peculiar, principalmente no que se refere a religiosidade popular. A ocupação do sul do Brasil por famílias oriundas do Arquipélago dos Açores foi uma estratégia interessante para coroa portuguesa, por diversos aspectos. A vida ligada as atividades primárias, agricultura e pesca, por exemplo, são características que os ilhéus possuíam, e, portanto, traze-los, poderia significar a prosperidade da região. Trazemos para este trabalho alguns resultados de trabalho de campo, observação participante e revisão teórica. É possível aferir que, pela situação de isolamento da península de São José do Norte, a cultura açoriana, herdada pelos habitantes, a vida ligada ao trabalho rural, pesca e agricultura ainda permeiam os hábitos locais, assim como a profunda religiosidade popular ligado a santos católicos, para os quais foram observados vários festejos e homenagens.
\end{abstract}

Palavras-Chave: São José do Norte, Memória, Identidade.

\section{Resumen}

El estudio tiene como objetivo reflexionar sobre algunos aspectos de la memoria social e identidad cultural en la península de San José del Norte, RS, específicamente sobre la etnicidad de las Azores. Los azorianos ocuparon la región en el mitad del siglo XVIII, trazendo para o Rio Grande do Sul modos de vida, tradiciones y culturas que, cuando se incorporan a las costumbres locales existentes, formaron una identidad peculiar luso-brasileña, especialmente con respecto a la religiosidad popular. La ocupación del sur de Brasil por las familias de las Azores fue una estrategia interesante para la corona portuguesa para varios aspectos. La vida se volvió la actividad primaria, la agricultura y la pesca, por ejemplo, son características que los isleños tenían, y así llevarlos, podría significar la prosperidad de la región. Traemos a este trabajo algunos resultados del trabajo de campo, observación participante y el examen teórico. Puede comprobar que el estado de aislamiento de São José do Norte Península, la cultura de las Azores, heredado por los habitantes, la vida vinculado al trabajo rural, la pesca y la agricultura todavía impregnan las costumbres locales, así como la profunda religiosidad popular vinculadas a los santos católicos, para los que se observaron diversas celebraciones y homenajes.

\footnotetext{
${ }^{1}$ Mestra em Memória Social e Patrimônio Cultural - Universidade Federal de Pelotas - UFPel; Professora na Universidade Federal do Pampa - Unipampa; Campus Jaguarão, Rio Grande do Sul, Brasil.

alessandrafarinha@unipampa.edu.br
} 
Palabras claves: São José do Norte, Memoria, Identidad.

\begin{abstract}
The study aims to reflect on some aspects of social memory and cultural identity in the Peninsula of São José do Norte, RS, specifically traces of Azorean ethnicity. Azoreans occupied the region in the mid-eighteenth century, bringing to Rio Grande land ways of life, traditions and cultures which, when incorporated into existing local habits, they formed a Luso-Brazilian identity peculiar, especially with regard to popular religiosity. The occupation of southern Brazil by families from the Azores was an interesting strategy for the Portuguese crown for various aspects. Life turned the primary activities, agriculture and fishing, for example, are features that the islanders had, and thus bring them, could mean the region's prosperity. We bring to this work some results of fieldwork, participant observation and theoretical review. You can check that the isolation situation at Peninsula of São José do Norte, the Azorean culture, inherited by the inhabitants, life linked to rural labor, fishing and agriculture still permeate the local habits, as well as the profound popular religiosity linked to saints Catholics, for which various celebrations and tributes were observed.
\end{abstract}

Keywords: São José do Norte, Memory, Identity.

\title{
1. Introdução
}

As terras sul-americanas, incluindo o Rio Grande do Sul, Uruguai e Argentina foram palcos de conflitos entre portugueses e espanhóis motivados, principalmente, pela ocupação e domínio das terras e riquezas. O Tratado de Tordesilhas, assinado no ano de 1494, não evitou estas disputas, e o estuário platino, neste contexto, tornou-se um dos pontos privilegiados. A ocupação europeia no estado ocorreu tardiamente em comparação ao restante da colônia. De acordo com Bunse (1981, p. 13), desde a chegada dos portugueses, o litoral do Rio Grande do Sul, embora conhecido, foi pouco explorado devido à sua configuração e a inacessibilidade da barra do Rio Grande, chamada posteriormente por Silva Paes de "Barra Diabólica".

Este trabalho objetiva refletir especificamente sobre a ocupação açoriana na península de São José do Norte, RS, em meados do século XVIII e sobre a herança cultural, os vestígios culturais desta etnia presente na região, legada pelos atuais moradores do local, principalmente com relação ao catolicismo popular.

Os açorianos trouxeram para terras rio-grandenses modos de vida, tradições e culturas que, incorporadas aos hábitos locais existentes, formaram uma identidade lusobrasileira peculiar. A ocupação do sul do Brasil por famílias oriundas do Arquipélago dos Açores foi uma estratégia interessante para coroa portuguesa, por diversos aspectos. A vida ligada as atividades primárias, agricultura e pesca, por exemplo, são características que os ilhéus possuíam, e, portanto, traze-los, poderia significar a prosperidade da região. Além disso, a ocupação hegemonicamente portuguesa garantiria, de certa forma, obediência a coroa e aos costumes da tradição lusa, como por exemplo as devoções católicas.

Estão neste trabalho alguns resultados da pesquisa de doutorado em andamento, provisoriamente intitulada "História e Memória da Mui Heroica Villa: A Festa Nossa 

e-ISSN 2016/Atual: 2525-7870 | e-ISSN 2015/2016: 2447-018X

Senhora dos Navegantes de São José do Norte - $R S^{\prime \prime}$, vinculada ao Programa de PósGraduação em Memória Social e Patrimônio Cultural da Universidade Federal de Pelotas. O método utilizado foi pesquisa de campo, com observação participante, além de revisão teórica, análise de documentos, fotografias antigas e registros fotográficos.

É possível aferir que, pela situação de isolamento da península de São José do Norte, a cultura açoriana, herdada pelos habitantes, a vida ligada ao trabalho rural, pesca e agricultura ainda permeiam os hábitos locais, assim como a profunda religiosidade popular ligado a diversos santos católicos, para os quais foram observados vários festejos e homenagens.

\title{
2. Breves aspectos históricos e geográficos da grandiosa península do RS
}

\begin{abstract}
Entre o oceano Atlântico e a Lagoa dos Patos situa-se, em forma de península, uma comprida faixa de terra numa extensão N-S de cerca de $250 \mathrm{~km}$ e numa largura que varia de 25 a $8 \mathrm{~km}$. Começa, ao norte, pouco abaixo de Palmares do Sul e termina, ao sul, à margem esquerda do Canal do Rio Grande. [...] Toda a região é uma imensa planície, sendo as únicas elevações as dunas ou cômoros [...]. A costa do Atlântico apresenta as mesmas características do litoral sul-brasileiro, sendo retilínea, sem acidentes, monótona a se perder no horizonte, sem enseadas ou ancoradouros. A costa da Lagoa doa Patos abre-se em várias enseadas, formadas por diversas "pontas" (BUNSE, 1981, p. 11).
\end{abstract}

Nesta grandiosa península, antigamente chamada de "Península do Pernambuco"2, indicada na Figura 01 encontra-se o município de São José do Norte, com território demarcado na cor vermelha no mapa abaixo. Historicamente, o território foi de suma importância no quadro geopolítico do começo da ocupação do estado, ocorrendo no lugar um incremento populacional e econômico que as estratégias de conflitos no Prata podem explicar. Na península, as lagoas ${ }^{3}$ se espalham no decorrer do litoral, sendo a maior delas a Lagoa do Peixe, que se comunica com o Oceano em determinadas épocas do ano e a faixa de dunas ${ }^{4}$ ao longo da praia e adentro.

\footnotetext{
${ }^{2}$ De acordo com o Primeiro Lustro da Diocese de Pelotas (1911-1916).

${ }^{3}$ Água doce, pouca profundidade e uma extensão no sentido N-S, paralelas à praia (BUNSE, 1981, p. 12).

${ }^{4}$ De vários tipos e de altura variável, mas não superior a 20 metros, a maioria sem vegetação, sendo, portanto, movediças, sofrendo a ação do vento que as desloca. Também existem as dunas fixadas pela vegetação, algumas, antigamente migratórias, encontram-se profundamente adentro, como em Mostardas e Estreito. Junto às dunas existe uma mata litorânea, baixa e raquítica (BUNSE, 1981, p. 12).
} 


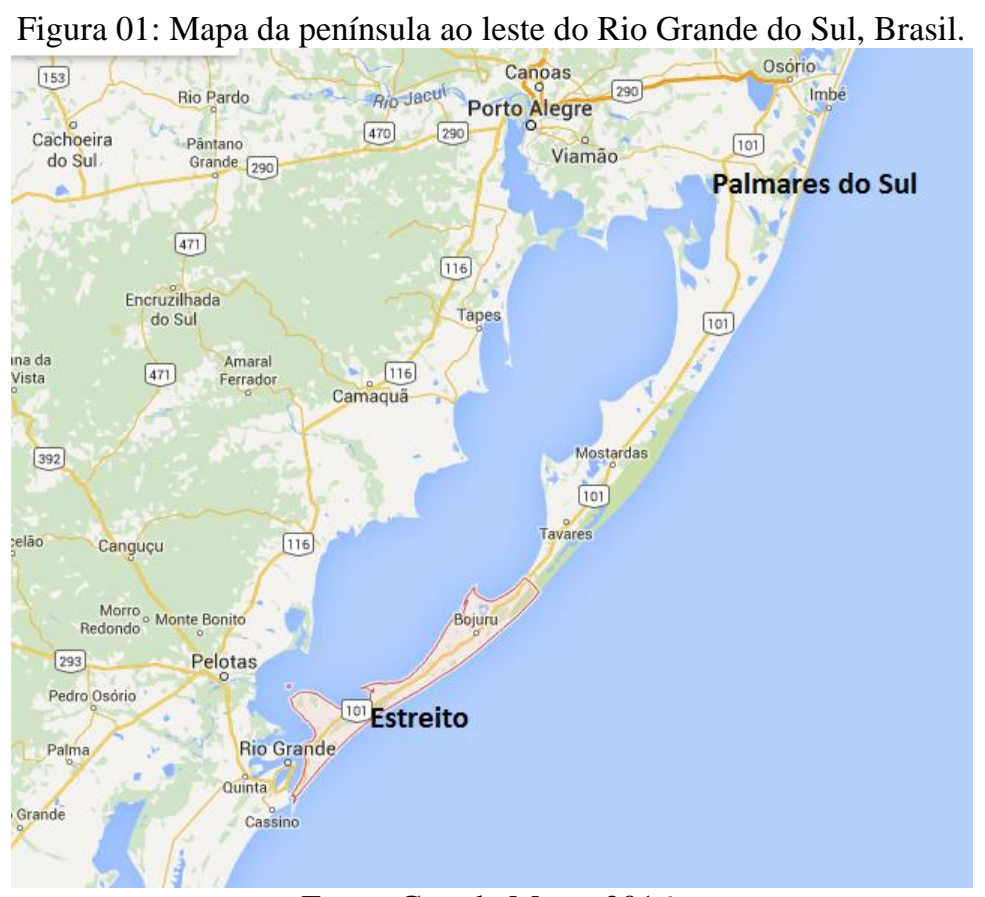

Fonte: Google Maps, 2016.

A escolha do lugar de origem dos futuros habitantes do sul do Brasil pode ter sido estratégica, por se tratar de um povo com habilidade no trabalho com as águas (pescado, navegabilidade), com a agricultura, famílias já constituídas (menor possibilidade de haver entre os imigrantes "aventureiros", que poderiam trazer qualquer desordem à colônia), hegemonicamente católicas (logo, “obedientes” à igreja e ao estado), por exemplo. De acordo com Pesavento (1985, p. 15), os chamados “casais d'El Rey" chegaram em grande quantidade em 1752, quando ocorreu o ponto alto da imigração ${ }^{5}$.

Um dos primeiros lugares a serem ocupados foi a região denominada de Estreito (localização indicada no mapa disposto na Figura 01). O Estreito, como o nome diz, é uma estreita faixa de terra da península entre a Laguna dos Patos e o Oceano Atlântico, distando cerca de 40 quilômetros do centro de São José do Norte. Ocorreu também no Estreito a primeira experiência de aldeamento indígena promovido pelas autoridades luso-brasileiras, sendo fundado um ano após a chegada dos primeiros açorianos, em 1753 (ALVES e TORRES, 1996, p. 07).

\footnotetext{
${ }^{5}$ Mesmo que tecnicamente seja uma imigração, é de praxe, na historiografia brasileira, referir-se a imigração para o processo iniciado a partir de 1824 com os alemães, e posteriormente outros tantos grupos. A vinda de colonizadores até o XVIII não é caracterizada como imigração.
} 

e-ISSN 2016/Atual: 2525-7870 | e-ISSN 2015/2016: 2447-018X

Bunse (1981, p. 12) afirma que o lugar era primitivamente habitado por índios carijó, cuja presença é lembrada na fala local e nos vestígios arqueológicos de panelas trazidas pelo arado da terra ou desenterradas pelo vento. De acordo com Alves e Torres (1996, p. 07), eram os índios minuano que habitavam os arredores, principalmente na Fazenda Real Bojuru, na época da chegada dos açorianos, pois há o registro de batizados dos mesmos no Forte de Sant'Ana do Estreito.

O nome da antiga capela existente no Estreito era Nossa Senhora das Candeias $^{6}$, e algum tempo após passou a se chamar Nossa Senhora da Conceição ${ }^{7}$ do Estreito. De acordo com Bunse (1981, p. 21), a capela foi construída pelo capelão dos índios minuano que viviam na Fazenda Real Bojuru.

A ideia principal era que os casais açorianos povoassem primeiramente a região das missões, e, com essa justificativa, de que não estavam em sua terra definitiva, levaram mais de 20 anos para receber suas prometidas terras. Além dos açorianos e índios minuano, já citados, há registro de outros povos que habitaram o Estreito neste período marcante da história da ocupação do território do estado. Por exemplo, durante a ocupação espanhola na vila do Rio Grande, de acordo com Bunse (1981, p. 16) no mínimo 60 famílias se refugiaram no Estreito, além de retirantes da Colônia do Sacramento, aumentando muito sua demografia e contribuindo para a fundação do local. Esta condição de refúgio para retirantes do Prata e do Rio Grande, aliada a questão de ponto privilegiado para um contra-ataque aos espanhóis, de retomada de Rio Grande ${ }^{8}$, deram, nessa fase da história, uma importância extraordinária à Península. Esta congregação populacional, hegemonicamente de origem portuguesa no entorno a capela de Nossa Senhora da Conceição foi, durante certo tempo, o ponto mais avançado dos portugueses, chamado de Fronteira do Norte (BUNSE, 1981, p. 19).

É válido salientar neste contexto que os habitantes do Estreito, após a chegada dos açorianos contribuíram com safras de trigo, incrementando consideravelmente a economia local. "Em 1787, já com 23 anos de cultura açoriana, a produção do trigo do Estreito é a maior da província, com 15.848 alqueires, representando $28 \%$ do total de 17 regiões produtoras" (LAYTANO, 1968, p. 57). É da cultura açoriana e do êxito no trabalho do campo

\footnotetext{
${ }^{6}$ Também chamada de Nossa Senhora da Candelária ou Nossa Senhora da Luz. Devoção de origem espanhola, surgida nas Ilhas Canárias no século XVI. Em pesquisa de campo em São José do Norte, um dos depoentes comentou que Nossa Senhora dos Navegantes também é chamada de Nossa Senhora das Candeias, pois à noite, a orientação dos barcos na escuridão se dá através de luzes, de candelabros que iluminam as águas, por isso, Candeias.

${ }^{7}$ Nossa Senhora da Conceição é a padroeira de Portugal.

${ }^{8}$ A retomada de Rio Grande ocorreu em 1776, em ataque liderado pelo tenente-general João Henrique de Boehm, com cerca de 2565 soldados. Os espanhóis foram definitivamente expulsos do Rio Grande do Sul.
} 
no Estreito que surgiu e prosperou às margens do canal, o povoado de São José do Norte (MATTOS, 1999, p. 26).

Porém a situação não permaneceu assim por muito tempo. Até o ano de 1812 a igreja de Nossa Senhora da Conceição do Estreito foi a matriz ${ }^{9}$. Após, devido ao restrito número de habitantes, a matriz passou a ser em São José do Norte, onde havia mais moradores e onde se havia erigido uma capela em honra a Nossa Senhora dos Navegantes. É possível que a primeira Festa de Navegantes, ocorrida já no ano anterior, 1811, tenha influenciado nesta decisão de transferência da matriz, já que tanto o porto quanto a cidade estavam em desenvolvimento.

A capela em honra a de Nossa Senhora da Conceição, no Estreito, foi atingida por uma tempestade e sepultada pelas areias, sendo recriada em 1846. Devido a vulnerabilidade com relação as tempestades de areia, foi transferida em 1872 para perto do Arroio Bojuru, ao sul da Fazenda Real. Assim surgiu a vila de Bojuru, em cuja capela, construída em 1882 ainda é venerada a de Nossa Senhora da Conceição do Estreito.

Esta breve explanação sobre a origem e ocupação do território de São José do Norte objetivou principalmente trazer fatos históricos, da constituição do território, aspectos geográficos, sobre as primeiras igrejas da antiga península, para então desenvolver reflexão sobre a ocupação açoriana e os traços verificados desta etnia no local, objeto principal deste trabalho. Quem eram esses portugueses? Como chegaram, de onde vieram, como viviam? Foram algumas perguntas norteadoras, fundamentais para a compreensão da história, das culturas e da origem das intensas devoções existentes em São José do Norte.

Podemos distinguir os diversos substratos que se sucedem: o indígena, lagunistas de Brito Peixoto, tropeiros de São Paulo e Minas, militares que vieram após a fundação da vila do Rio Grande de São Pedro para as guarnições costeiras, gente dos mais diferentes lugares do Brasil e de Portugal, fazendeiros que receberam sesmarias na região e retirantes do Prata. Todos esses, porém, em número relativamente diminuto, esparsos e perdidos na imensidade da região [...] Tal somente sucedeu após a chegada do elemento açoriano que, superpondo-se àqueles substratos, vai formar o verdadeiro "stratum" humano da região (BUNSE, 1981, p. 27).

De acordo com Jancsó e Kantor (2001, p. 12), as novas sociabilidades que surgiram no decorrer dos anos tornaram-se indicadoras da emergência de novas identidades

\footnotetext{
${ }^{9}$ De acordo com Bunse (1981, p. 22), há controvérsias quanto à essa informação já que Saint-Hilaire, em passagem pela região em 1820, afirma que o Norte pertencia a freguesia do Estreito. Porém, será adotada a data de 1812 como referência.
} 
simultaneamente políticas, religiosas, sociais e étnicas, configurando parte importante de um processo de legitimação do lugar.

\section{Vestígios étnicos: memória, cultura e identidade Luso-brasileira}

As sociedades sejam elas primitivas, arcaicas ou modernas são embasadas no mesmo grupo social, que é a família. A sua organização e funcionamento está solidamente assentada em seus valores e tipo de trabalho social exercido, é isso que dá estabilidade à sociedade (AMARAL, 1999, p. 275).

A vinda em massa de açorianos em meados do século XVIII para o sul do Brasil foi mantida em sigilo pela coroa portuguesa naqueles tempos, pois esta preferência dada à uma ocupação de portugueses do continente e ilhéus açorianos, em detrimento dos portugueses sulistas, e outros possíveis, poderia gerar mal estar, tanto entre portugueses já residentes no Brasil quanto com castelhanos (AMARAL, 1999, p. 272).

Conforme já colocado, a ocupação do sul por famílias açorianas foi uma estratégia interessante para coroa portuguesa, por diversos aspectos. A vida ligada as atividades primárias, agricultura e pesca, por exemplo, são características que os ilhéus possuíam, e, portanto, poderiam traze-las, fazendo prosperar o sul do Brasil. Neste âmbito, foi importante a similaridade geográfica do território de São José do Norte e das Ilhas dos Açores.

Foram requisitadas em edital, famílias já constituídas para virem ao Brasil. Desta forma, além de ocupar a península, os açorianos poderiam ter mais filhos, trabalhariam na terra, com a agricultura e nas águas (com diversas possibilidades de pescados, de água doce e/ou salgada), com a pesca artesanal, fazendo aumentar a demografia (com portugueses legítimos e seus descendentes) e prosperar economicamente o lugar e a colônia como um todo.

Os açorianos, ao chegarem ao sul do Brasil, não encontraram um perfil étnico hegemônico, organizado, em equilíbrio. De acordo com Amaral (1999, p. 283), havia militares, principalmente de Minas Gerais, alguns portugueses de Rio Grande, outros remanescentes de Colônia do Sacramento, de São Paulo, Rio de Janeiro, poucos estrangeiros, poucos escravos e índios. Era uma população eclética, com pouca ou nenhuma integração. Ao contrário disso, os açorianos chegam com uma cultura partilhada, organização no trabalho e hierarquias, com tradições religiosas e de lazer (festas, danças, folclore) consolidadas, possivelmente passando a consistir em uma "referência" para outros povos habitantes locais, por essas qualidades coletivas. 

e-ISSN 2016/Atual: 2525-7870 | e-ISSN 2015/2016: 2447-018X

Entre a população existente e os açorianos houve um processo de aculturação, sendo que a contribuição deste último foi muito maior para aqueles. As pessoas fora do grupo açoriano passaram a viver sua cultura, absorvendo-a a cada dia. Essa contribuição se deu na forma de trabalhar a terra, no acompanhamento de seus rituais religiosos, na maneira de se utilizar da pesca, no seu linguajar, nas suas festas e na forma como construíam suas casas [...] que deixaram marcas na maneira de ser a agir dos rio-grandenses (AMARAL, 1999, p. 284).

Conforme o trecho acima, a maneira de ser do açoriano foi imperiosa no território, e incorporada, de certa forma, pelos que já residiam no Brasil. A herança social e cultural foi transmitida por gerações, e assim cultivados os valores e princípios, salientando as relações familiares como fundamentais nesse processo. Foram estudadas obras que descreveram o perfil psicológico, social e físico dos açorianos. Lima (1935, p. 54), por exemplo, afirma que o tipo físico do açoriano era diferenciado pelos exercícios diários e constantes da vida agrícola e marítima:

A classe baixa é muito laboriosa e entrega-se de preferência à agricultura e à vida do mar. É a mais frugal do mundo, porque assim lhe permite a doçura do clima; e deixa com facilidade o solo natal quando esse lhe é pouco propício. Odeia a vida militar, mas no campo de batalha é fiel a disciplina e dá prova de valor (LIMA, 1935, p. 55).

O historiador Accursio Ramos, citado por Amaral (1999, p. 274) também descreve o açoriano como sendo mais trabalhador, laborioso do que o português do continente, mais "econômico, pacífico, afetuoso e amável". Esta autora também salienta características sociais da etnia açoriana: "o amor ao trabalho, à propriedade territorial e ao solo natal, a disciplina, a religiosidade, a hospitalidade e a solidariedade" (AMARAL, 1999, p. 174). Aspectos que corroboram com Lima (1935, p. 54), quando afirma que nos Açores era cultivado em alto grau o sentimento da hospitalidade, de onde parte a sensibilidade do povo.

Conforme já enfatizado, uma das culturas a prosperar com a chegada dos açorianos foi a do plantio do trigo ${ }^{10}$. Além deste, milho, feijão, lentilha, mandioca, centeio, alpiste, vinha, além de legumes e verduras (Amaral, 1999, p. 278). Por outro lado, não apenas os açorianos trouxeram seu legado, mas também se incorporaram as práticas e demandas locais, como por exemplo, a lida do gado. Algumas sesmarias foram com o tempo sendo transformadas em estâncias. Com o surgimento do charque na região como produto de exportação, alguns descendentes de açorianos enriqueceram com a venda de gado para as charqueadas.

\footnotetext{
${ }^{10}$ De acordo com Bunse (1981, p. 28), no ano de 1780 a localidade apontou como uma a maior produtora de trigo do Estado.
} 
Porém, no decorrer do século XIX, uma série de fatores desfavoreceram economicamente a região. Houve a decadência do trigo, a antiga estrada que ligava o Rio Grande até a capital foi substituída pelo transporte fluvial. As imigrações do século XIX privilegiaram outras regiões do estado, para uma nova fase da agricultura. Por outro lado, pode-se afirmar que com esse distanciamento dos centros receptores de imigrantes, com o difícil acesso, a península ficou de certa forma "protegida". De acordo com Bunse (1981, p. 29), a localidade conservou traços originais das suas antigas tradições, dentre elas, a tradição religiosa.

\section{Uma viagem pela religiosidade luso-brasileira}

Dentre as tradições e costumes trazidos pelos açorianos, já mencionados, a religiosidade é um dos mais presentes no lugar. A vida religiosa local foi uma das bases da atividade social. A participação em sacramentos, batismos, crisma, missas e festas religiosas permearam o lugar, transmitindo, de certa forma, essa forma cultural. Era em torno de capelas se formavam os agrupamentos humanos. Havia uma capela em Mostardas, uma no Estreito, em honra a Nossa Senhora da Conceição, e outra em Bojuru.

Conforme Bunse (1981, p. 29), a construção de uma capela significava que a vizinhança rural já estava suficientemente desenvolvida, e que poderia futuramente ser uma freguesia. A coroa portuguesa empenhou-se em garantir aos açorianos a devida assistência religiosa no Brasil, através de Provisão Régia, assim transcrita ${ }^{11}$ : “[...] E porquanto o primeiro cuidado que deve ter-se é que todos os ditos colonos sejam assistidos de parte espiritual e sacramentos e em cada um dos ditos lugares fará logo o dito brigadeiro levantar logo uma igreja [...]".

A marca do legado da religiosidade açoriana é evidente nas duas mais tradicionais festas em honra a Nossa Senhora dos Navegantes ${ }^{12}$, em Porto Alegre, primeiro local onde os açorianos chegaram, contribuindo para a sua fundação. Em Porto Alegre a procissão do dia 02 de fevereiro chega a reunir, de acordo com Steil (2004, p. 13) cerca de um milhão de devotos e peregrinos. O mesmo fenômeno ocorre em São José do Norte, onde ocorre provavelmente a festa de Navegantes mais antiga do Brasil, desde 1811, sendo também uma herança da cultura açoriana.

\footnotetext{
11 Trecho da Provisão Régia encontrado em Bunse (1981, p. 38).

12 A invocação de Nossa Senhora dos Navegantes é muito usada entre os pescadores, homens modestos que diariamente enfrentam o furor das ondas à procura do sustento para suas famílias.
} 
RELACult - Revista Latino-Americana de Estudos em Cultura e Sociedade

Revista Latinoamericana de Estudios en Cultura y Sociedad | Latin American Journal of Studies in Culture and Society V. 02, Ed. Especial, dezembro, 2016, p. 815-830| periodicos.claec.org e-ISSN 2016/Atual: 2525-7870 | e-ISSN 2015/2016: 2447-018X

A Figura 02 mostra, respectivamente, a Festa de Nossa Senhora dos Navegantes de São José do Norte em meados do século XX e atualmente.

Figura 02: Festa de Nossa Senhora dos Navegantes de São José do Norte, à esquerda na metade do século XX, à direita, em 2014.

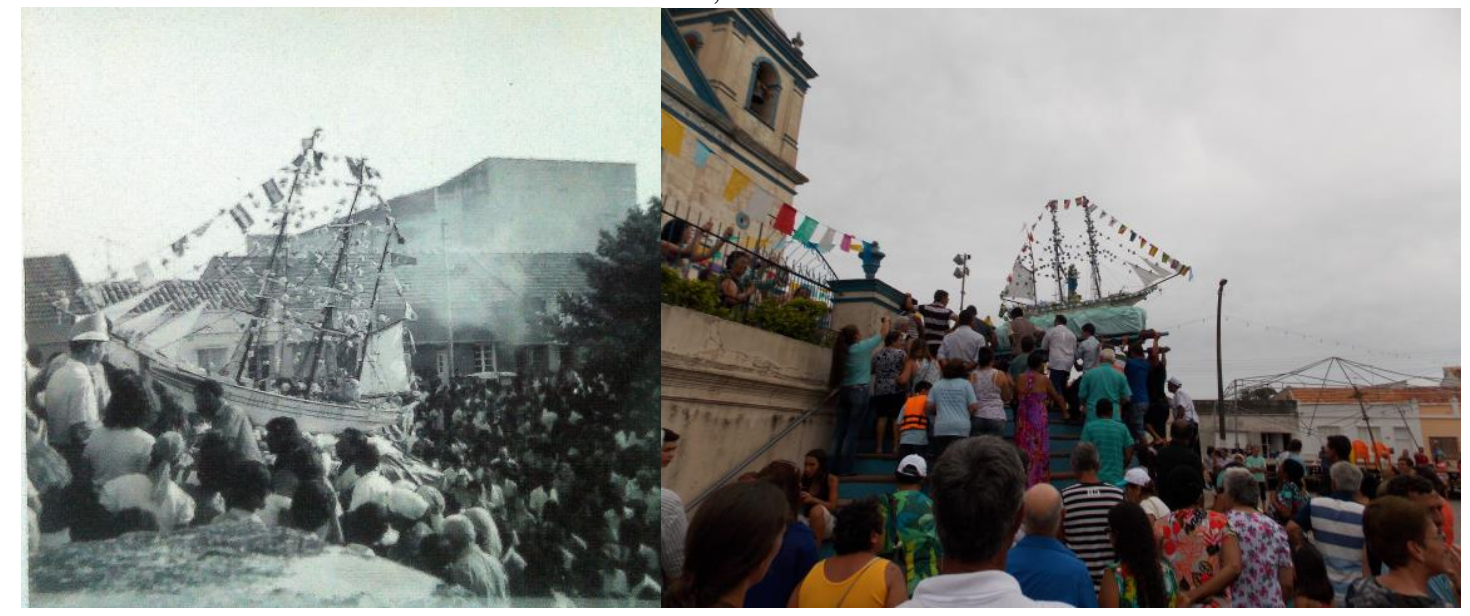

Fonte: Da autora.

A intensa devoção em Nossa Senhora dos Navegantes em São José do Norte, considerada um dos vestígios culturais dos açorianos na península, pode estar relacionada ao principal modo de subsistência do lugar, ligado às águas, à pesca, à periculosidade do trabalho marítimo. A proteção destes trabalhadores, há mais de dois séculos, está nas mãos da Virgem Maria. As motivações para a festa de Navegantes, portanto, são de agradecimento, de louvor, de promessas, caracterizando uma intensa expressão do catolicismo popular.

A Figura 03 mostra, no interior da península de São José do Norte, uma pequena igreja, em honra ao Sagrado Coração de Jesus, localizada na vila de pescadores da Várzea, em meados do século XX.

Figura 03: Igreja Sagrado Coração de Jesus, na Várzea. 


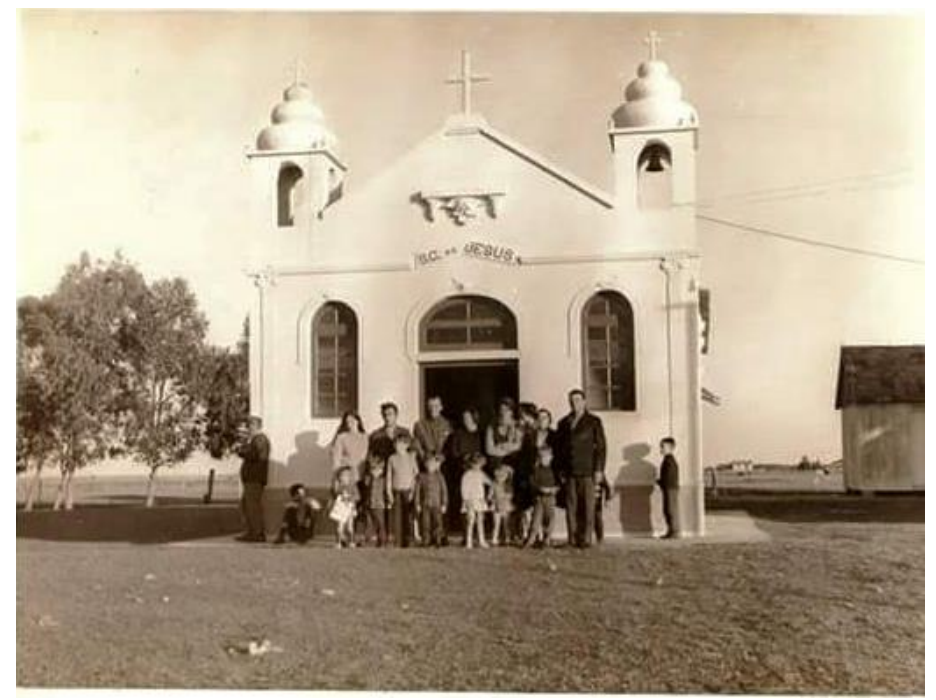

Fonte: acervo particular de depoentes

Percebe-se na antiga fotografia que, no entorno da igreja há um vasto campo, poucas casas. $\mathrm{O}$ acesso era dificultado, as pequenas vilas que se formavam eram distantes (observa-se o mapa disposto na Figura 01). A igreja é a referência, as festas religiosas eram a motivação para o encontro, a celebração, comemorações entre as famílias ocorriam em ocasiões de festas religiosas, sacramentos, batismos, casamentos - principal meio de socialização. Em saída de campo, visitando esta comunidade, foi possível verificar que esta igreja encontra-se em bom estado de conservação. Foi possível perceber que a forma de viver não modificou muito na vila de pescadores, onde a eletricidade chegou há poucos anos.

A igreja e as festas religiosas permanecem sendo o motivo principal para sair, para passear, encontrar amigos e parentes. A memória dos depoimentos, das fotografias antigas, a história relatada nos livros, é recorrente nas comunidades distantes, espalhadas na grande península. São repetidos os ofícios, a fé, a organização da vida, como afirma Assmann (2006), na teoria da memória cultural, geracional. Esta organização das famílias para visitar parentes em outras vilas de pescadores, distantes se dá a partir do mês de comemoração dos santos, do calendário litúrgico da igreja católica. Onde há igreja em honra a este santo, quando chega o mês, tem festa, todos podem ir.

Esta união coletiva em torno das festas católicas, essa hegemonia do catolicismo na península foi um forte traço étnico da etnia açoriana encontrado na localidade. Foi registrada uma dessas festas, como se pode ver na Figura 04, na igreja Sagrado Coração de Jesus, da Várzea, os estandartes e os representantes das diversas comunidades. 
RELACult - Revista Latino-Americana de Estudos em Cultura e Sociedade

Revista Latinoamericana de Estudios en Cultura y Sociedad | Latin American Journal of Studies in Culture and Society V. 02, Ed. Especial, dezembro, 2016, p. 815-830| periodicos.claec.org e-ISSN 2016/Atual: 2525-7870 | e-ISSN 2015/2016: 2447-018X

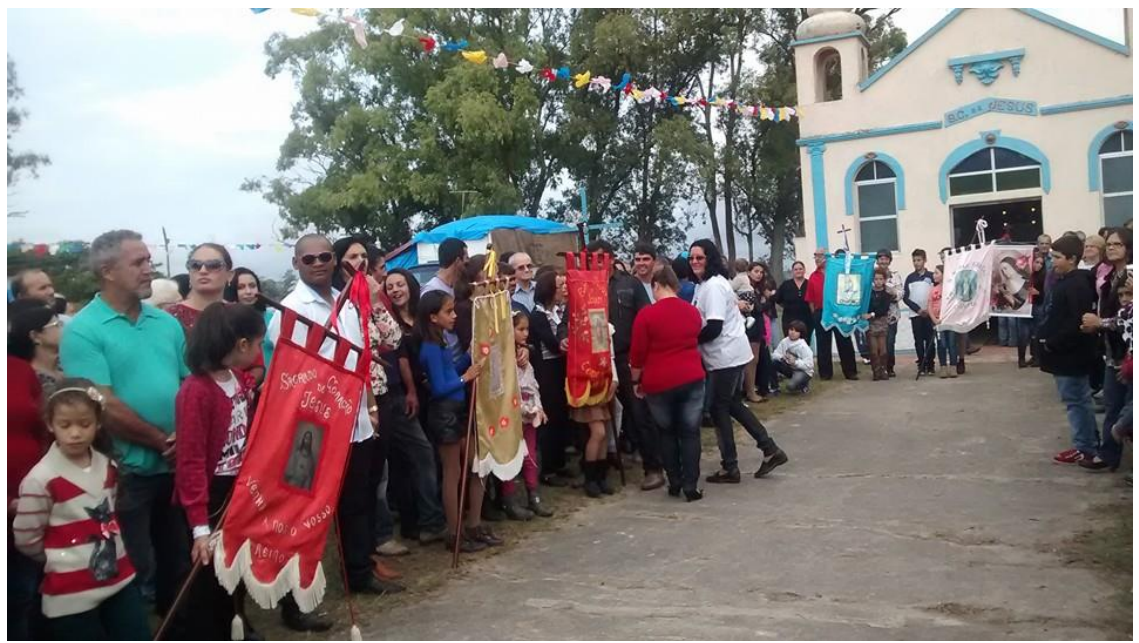

Fonte: acervo particular de depoentes

Nas festas religiosas das comunidades da península de São José do Norte, há momentos para o sagrado e para o profano. Conforme visto na Figura 04, nas missas festivas cada comunidade se faz representar por meio de estandartes com imagens dos santos, procissões, ofertas, cânticos, súplicas de graças, havendo o ritual católico formal, instituído. Há também o momento da festa profana, o churrasco, galeto, almoço, bailão, jantar dançante, em cerca de dois dias de festa (de acordo com a fala popular, na sexta-feira à noite as famílias começam a chegar, no domingo à noite encerra). Na Figura 05 pode-se ver o chamado bolante, um chalé de madeira que é levado por cada família para as festas religiosas, onde podem dormir, durante o período da festa. Nestas ocasiões, os bolantes ficam nos pátios, nos arredores da igreja, nas casas de parentes, e o uso do banheiro é feito nas casas dos moradores da comunidade ou na própria igreja.

Figura 05: Bolante (pequeno chalé levado para as festas religiosas, para pouso das famílias).

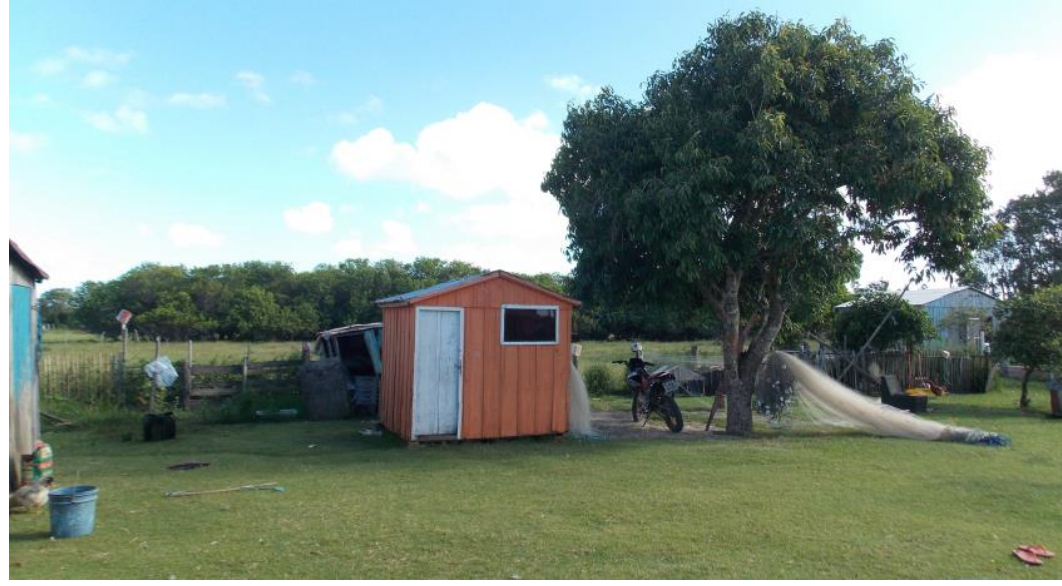

Fonte: Da autora 
RELACult - Revista Latino-Americana de Estudos em Cultura e Sociedade

Revista Latinoamericana de Estudios en Cultura y Sociedad | Latin American Journal of Studies in Culture and Society V. 02, Ed. Especial, dezembro, 2016, p. 815-830| periodicos.claec.org e-ISSN 2016/Atual: 2525-7870 | e-ISSN 2015/2016: 2447-018X

Houve, no decorrer do século XX, certa decadência na vida religiosa local, diagnosticada pela queda no número de sacramentos realizados, falta de párocos, e outras decorrências. Porém, o sentimento religioso, aparentemente, não se perdeu, foi cultivado no interior das famílias, das casas humildes, das pequenas comunidades. É grande a veneração de santos católicos, principalmente portugueses, promessas, reza do terço, e as tradicionais festas religiosas (BUNSE, 1981, p 38). As Figuras 05 e 06 mostram a festa de Nossa Senhora da Conceição no Estreito, primeira evocação católica mariana no local onde começou a ocupação açoriana da península, conforme descrito no breve histórico do item 2.

Figura 02: Festa em honra a Nossa Senhora da Conceição no Estreito, 2015.

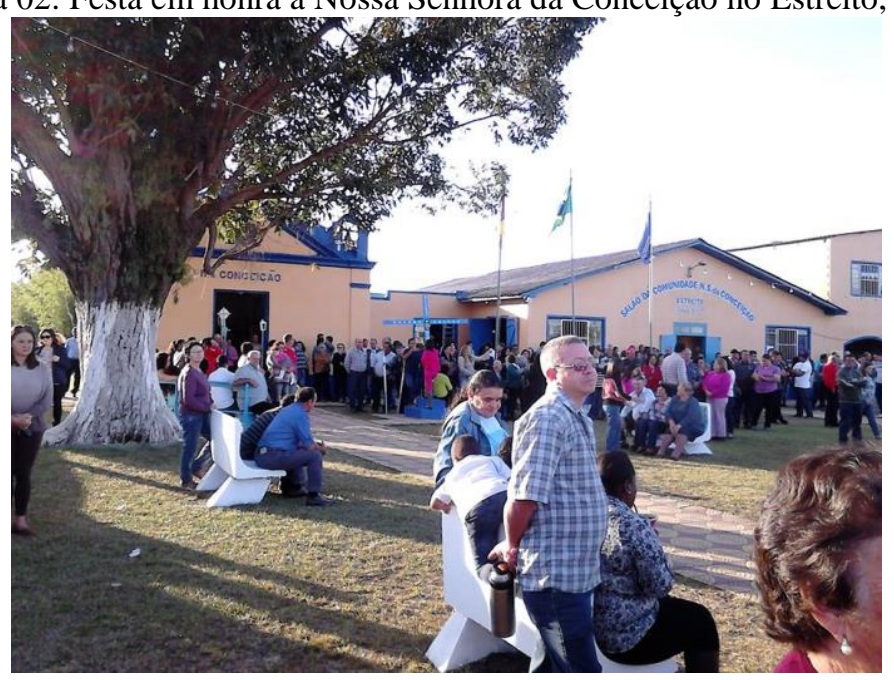

Fonte: Da Autora.

Figura 03: Casas e tendas decoradas para a Festa em honra a Nossa Senhora da Conceição no Estreito, 2015.

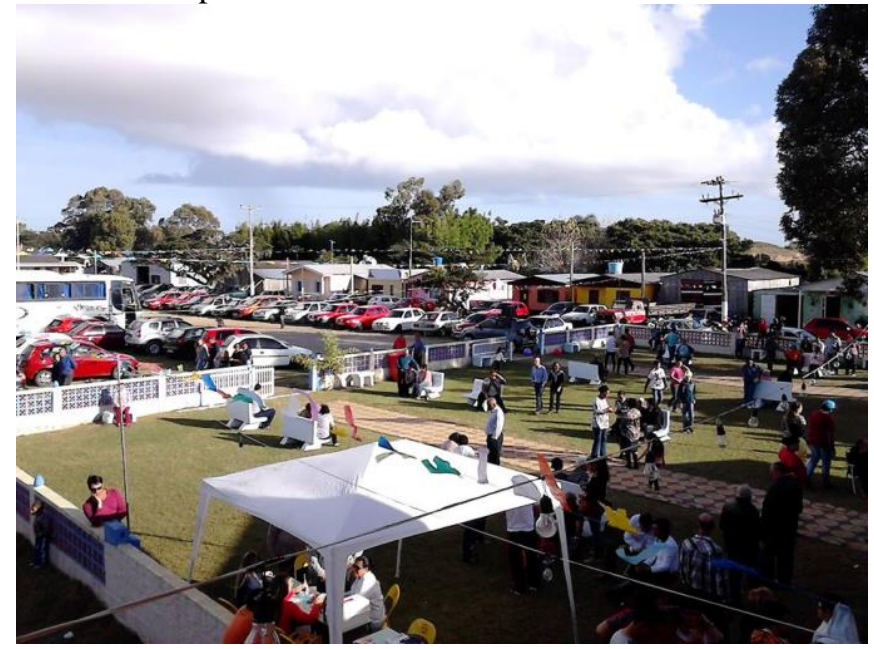

Fonte: Da Autora. 

e-ISSN 2016/Atual: 2525-7870 | e-ISSN 2015/2016: 2447-018X

Percebe-se nas fotografias que o catolicismo popular ainda permeia a localidade do Estreito, onde começou a ocupação da península pelos açorianos. Os automóveis e ônibus no estacionamento da igreja indicam a presença de vários devotos, a considerar que é uma festa regional de uma distante vila de pescadores. Conforme dito, a base da economia local, até hoje em São José do Norte é a pesca e a agricultura, ambas culturas aperfeiçoadas com as técnicas e tradições açorianas. O catolicismo popular é vinculado ao agradecimento pela dádiva da terra e das águas, pode se dizer que há uma ligação entre a religiosidade e o território, a forma de subsistência. Cultua-se na península vários santos de devoção católica, marca do catolicismo popular luso-brasileiro, principalmente em lugares de difícil acesso, através de festas religiosas, importantes meios de socialização local e vestígios dos açorianos na grande península do Rio Grande do Sul.

\section{Considerações finais}

Os povos da península ibérica, bem como os povos latinos, possuem forte ascendência religiosa, vivenciada no acompanhamento dos ritos da Igreja Apostólica Romana. Esta exercia grande influência em toda a América Latina - espanhola e portuguesa [...]. O Rio Grande de São Pedro foi colonizado, inicialmente, pelos brasileiros paulistas, fluminenses e mineiros, chegando, posteriormente, os colonizadores lusos do continente e dos Açores, bem como da Ilha da Madeira. Para eles os rituais católicos do batismo e crisma, casamento e ritos funerários são seguidos à risca (AMARAL, 1999, p. 215).

No começo da descrição deste objeto, antes de uma pesquisa histórica direcionada, já era se tinha o conhecimento de que a ocupação de São José do Norte por casais açorianos poderia ter profunda influência na cultura local. No decorrer da escrita, durante o estudo sobre a história local, sobre esta etnia lusa, sobre o processo de vinda das famílias açorianas, sua cultura, atividades tradicionais, foram sendo identificados aspectos que demonstram que as similaridades entre os açorianos e o que percebemos na cultura local em São José do Norte permeia questões territoriais, geográficas, do catolicismo popular, tradições familiares, modos de subsistência.

A religiosidade ligada a religião católica, por exemplo, era presente desde os primeiros anos de ocupação de São José do Norte. Isso devia-se, não apenas por causa dos costumes trazidos e reproduzidos pelos portugueses, mas também pela influência da autoridade militar local. Segundo Amaral (2009, p. 216), quaisquer práticas religiosas eram reguladas pelos militares. A população era coagida a participar das missas, em horário determinado por militares encarregados, sob pena de prisão se a determinação não fosse cumprida. As ordens dos governadores e capitães gerais eram de que se alguém sem justo motivo não comparecesse a solenidades públicas, procissões e ofícios religiosos, seria preso. 
Fala-se aqui especificamente de devoções católicas que indiscutivelmente são vestígios culturais de colonizadores portugueses, e neste caso açorianos, porém vale ressaltar que são tradições que, desde o início, e ao longo dos anos, foram constantemente ressignificadas e incorporadas de diversos aspectos brasileiros, com inferência também de etnias e culturas distintas, o que torna o fenômeno do estudo da cultura local, abrangente e heterogêneo, de profundo interesse interdisciplinar.

$\mathrm{O}$ aspecto do isolamento da península também torna o estudo mais desafiador, pois se ali se cultiva o simples, o pacato, as relações vicinais, de camaradagem, de partilha e comunhão. Se conhece a vida e a dificuldade de cada família, as vizinhas cuidam dos filhos das outras, há solidariedade, vida em comunidade, no verdadeiro sentido da palavra. Algo que, ao atravessar o canal Miguel da Cunha, chegando em Rio Grande, não é possível, não é visto com tanta naturalidade. Pode se ressaltar a vulnerabilidade dessas relações de sociabilidade na península de São José do Norte, pelas modificações no uso do solo, incentivo de outras culturas, como o pinus, por exemplo, investimento em obras portuárias dentre vários fatores que colocam as atividades tradicionais em risco.

\section{Referências}

ALVES, Francisco das Neves e TORRES, Luiz Henrique. Ensaios de História do Rio Grande do Sul. Rio Grande: Editora da FURG, 1996.

AMARAL, Ivone Leda do. A sociedade de Nossa Senhora da Conceição do Estreito e Contribuição Açoriana na Formação Cultural do Rio Grande de São Pedro. In: JACCOTTET, Alda Maria de Moraes (org.). A largueza histórica do Estreito. Pelotas: Editora Universitária, 1999.

BARCELLOS, Rubens de. Estudos Rio-Grandenses. Coleção Província. Vol. 07. Porto Alegre: Globo, 1955.

BUNSE, Heinrich. São José do norte: Aspectos linguístico-etnográficos do antigo município. Porto Alegre: Mercado Aberto, 1981.

COSTAMILAN, José Fernando e TORRES, Luiz Henrique. São José do Norte: o início de um povoamento. Rio Grande: Fundação Universidade do Rio Grande, 2007.

IBGE, Instituto brasileiro de geografia e estatística. Senso demográfico de 2010. Disponível em: http://www.censo2010.ibge.gov.br/sinopse/index.php?dados $=21 \& u f=43$ Acesso em 10 jul 2015.

JANCSÓ, István e KANTOR, Iris (org.). Festa: Cultura e sociabilidade na América Portuguesa. São Paulo: Hucitec, 2001. 

e-ISSN 2016/Atual: 2525-7870 | e-ISSN 2015/2016: 2447-018X

LAYTANO, Dante de. Os Açorianos. In: BECKER, Klaus. Enciclopédia Riograndense $1^{\circ}$ volume. Porto Alegre: Sulina, 1968.

MATTOS, Mario Barboza de. Estreito: glória sob as areias. In: JACCOTTET, Alda Maria de Moraes (org.). A largueza histórica do Estreito. Pelotas: Editora Universitária, 1999.

PESAVENTO, Sandra Jatahy. História do Rio Grande do Sul. Porto Alegre: Mercado Aberto, 1985. 